\title{
Quantitave and Qualitative Interferences of Pentoxifillyne on Hepatic Schistosoma mansoni Granulomas: Effects on Extracellular Matrix and Eosinophil Population
}

\author{
Luis Felipe Reis, Túlio Galvão Ventura, Sônia Oliveira Souza*, Arturo Arana- \\ Pino**, Marcelo Pelajo-Machado**, Mario José S Pereira**, Henrique Leonel

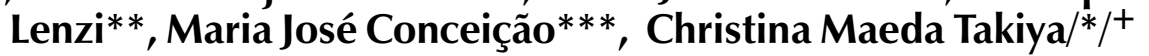

\begin{abstract}
Faculdade de Medicina, Universidade Federal do Rio de Janeiro *Serviço de Anatomia Patológica, Hospital Universitário Clementino Fraga Filho, Universidade Federal do Rio de Janeiro, Av. Brigadeiro Trompowsky s/nº, Cidade Universitária, 24921-590 Rio de Janeiro, RJ, Brasil **Departamento de Patologia ***Departamento de Medicina Tropical, Instituto Oswaldo Cruz-Fiocruz, Rio de Janeiro, RJ, Brasil
\end{abstract}

Mast cells and eosinophils actively participate in tissue repair and are prominent components of Schistosoma mansoni granulomas. Since pentoxifillyne (PTX) is an immunomodulatory and antifibrotic substance, we aimed to characterize, by morphological techniques, the effect of this drug on fibrosis developed inside murine hepatic schistosomal granulomatous reaction, beyond the quantification of eosinophil and mast cell populations. The drug (1 mg/100 g animal weight) was administrated from 35 to 90 days post-infection, when the animals were killed. The intragranulomatous interstitial collagen network was analyzed by confocal laser scanning microscopy, the number of eosinophils and mast cells was quantified and the results were validated by t-student test. Treatment did not interfere on the granuloma evolution but caused a significant decrease in the total and involutive number of hepatic granulomas $(p=0.01$ and 0.001 , respectivelly), and in the intragranulomatous accumulation of eosinophils $(p=0.0001)$. Otherwise, the number of mast cells was not significantly altered $(p=0.9)$; however, it was positively correlated with the number of granulomatous structures $(r=0.955)$. In conclusion, PTX does not affect development and collagen deposition in S. mansoni murine granuloma, but decreases the intragranulomatous eosinophil accumulation possibly due to its immunomodulatory capability, interfering in cellular recruitment and/or differentiation.

Key words: mast cell - eosinophil - collagen - pentoxifylline - Schistosoma mansoni

Increasing evidence ascribes to mast cells and eosinophils a crescent role in the development of inflammation and fibrosis (Hibbs et al. 1982, Davis et al. 1984 Bienenstock et al. 1987). In schistosomiasis, hepatic portal fibrosis is consequent to fibroblastic stimulation and excessive extracellular matrix accumulation (Friedman 1993), but the potential participation of both referred cell types in this situation is not well characterized. In chronic infection, the number of eosinophil precursors increases in the bone marrow and in extramedullary myelopoietic foci (Borojevic et al. 1981, Lenzi et al. 1987) due not only to bone marrow production but, similarly to a monomacrophagic population, to their accelerated release from bone marrow into the blood

\footnotetext{
This work was supported by a grant from the CNPq. ${ }^{+}$Corresponding author. Fax: +55-21-2562.2669. E-mail: takiyacm@hucff.ufrj.br

Received 14 May 2001

Accepted 25 July 2001
}

and to their amplification in peripheral tissues (El Cheik \& Borojevic 1993). The mast cell population, on the other hand, presents a bimodal pattern inside hepatic granulomas expressed by transient increases and decreases (Lenzi et al. 1997), and in chronic infection the population seems to be maintained by cytokines such as IL-3 and IL-9, T-cell derived factors (Khalil et al. 1996) and also, in part, by the induction of a stem cell factor from hepatic stellate cells (Brito \& Borojevic 1997). Since collagen degradative substances are not available for therapeutic use, control of fibrosis formation seems to be the primary goal in fibrosis prevention. Pentoxyfilline (PTX), a methylxantine phosphodiesterase inhibitor, has been found to have an antiproliferative effect on cytokine induced mitogenesis on fibroblasts and myofibroblasts, reduces transdifferentiation of myofibroblasts and causes inhibition of extracellular matrix synthesis (Berman \& Duncan 1989, Curt et al. 1994, Duncan et al. 1995, Windmeier \& Gresser 1996, Preaux et al. 1997, Insbrucker \& Peterson 1998). PTX can interfere on a large spectrum of cytokines with proinflammatory 
actions, such as TNF- $\alpha$, IL-2, IFN- $\gamma$ and IL-1 (Bienvenu et al. 1995), which also affect the schistosomal granuloma development (Boros \& Lukacs 1992, Cheever et al. 1992).

The aim of this work was to characterize the impact of PTX administration on the Schistosoma mansoni granuloma collagen network as well as on the mast cell and eosinophil population.

\section{MATERIALS AND METHODS}

Animals - Thirty outbred, young, male, Swiss Webster mice were infected percutaneously with 50 cercariae of $S$. mansoni (Café strain), obtained from stool eggs of a hepatosplenic patient from an endemic area (Capitão Andrade, MG, Brazil) and freshly eliminated from Biomphalaria glabrata, raised in the laboratory. They were separated in two main groups and four subgroups - Infected (I) $(\mathrm{n}=15)$; Infected and treated (I+PTX) $(\mathrm{n}=15)$, and controls - $\operatorname{Normal}(\mathrm{N})(\mathrm{n}=5)$ and Normal and treated animals $(N+P T X)(n=5)$. Animals were housed with controlled temperature and light environment and fed water and commercial chow ad libitum. Both infected animal subgroups were killed on the 90th day post infection (PI) together with paired control mice.

Drug - PTX (Trental $\left.{ }^{\circledR}\right)$ was intraperitoneally administered from day $35 \mathrm{PI}$, in the dose of $1 \mathrm{mg} / 100$ $\mathrm{g}$ animal weight/animal, for 55 days (5 days/week).

Histology - Liver fragments were fixed in $10 \%$ buffered, dehydrated and paraffin embedded formaldehyde. Five $\mu \mathrm{m}$ sections were stained with hematoxylin/eosin, Alcian blue pH 1.0 and 2.5, Siriusred pH 10.5 for eosinophils (Bogomoletz 1980) and phosphomolibid-acid-picro-sirius red (PMA-PSR) for interstitial collagens (Dolber \& Spach 1993).

Collagen network - PMA-PSR slides were observed by confocal laser scanning microscopy (LSM 410, Zeiss), considering exudative-productive and involutive granulomas with central eggs (5 granulomas/animal).

Quantitative analysis - Twenty fields of $1 \mathrm{~mm}^{2}$ per slide (total area per animal $=20 \mathrm{~mm}^{2}$; total area per subgroup $=100 \mathrm{~mm}^{2}$ ) were analyzed by bright field microscopy using $\mathrm{x} 40$ objective lens and $\mathrm{x} 10$ eyepiece (Zeiss) calibrated with a millimetric reticule (Leitz).

Granuloma counting - Only transversal sections of granulomas, stained with hematoxylin/ eosin, showing central viable eggs were considered. Granulomas were classified according to Lenzi et al. (1998) being discriminated from exudative to involutional stages.

Cell counting - Mast cells and eosinophils present inside granulomas were counted in alcianblue $\mathrm{pH} 2.5$ and sirius-red pH 10.2 (Bogomoletz 1980) liver stained sections, respectively.
Statistical analysis - Results were validated by impaired T-test and significance was determined with the use of $p$ value $<0.05$, and linear regression.

\section{RESULTS}

The various stages of granuloma evolution were present in both subgroups of infected animals (without or with treatment), with clear predominance of exudative-productive and productive ones. In the I+PTX subgroup, a significant decrease of the total and involutive number of granulomas $(p=0.01$ and $p=0.001$, respectively) was observed when compared with the infected non-treated mice (Figs $1,2)$.

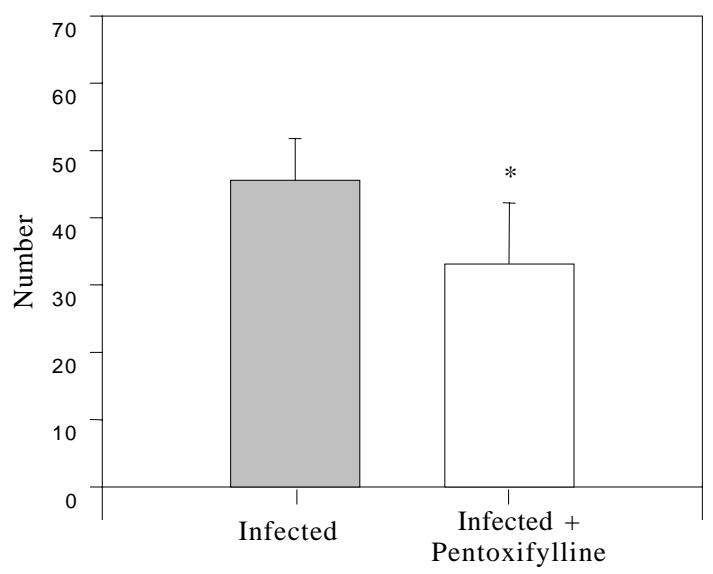

Fig. 1: granulomas number in infected subgroups. A significative diminution of hepatic Schistosoma mansoni granuloma number is depicted in the infected and treated with pentoxifylline (Infected+PTX) subgroup when compared with the only infected one $(\mathrm{p}=0.01)$.

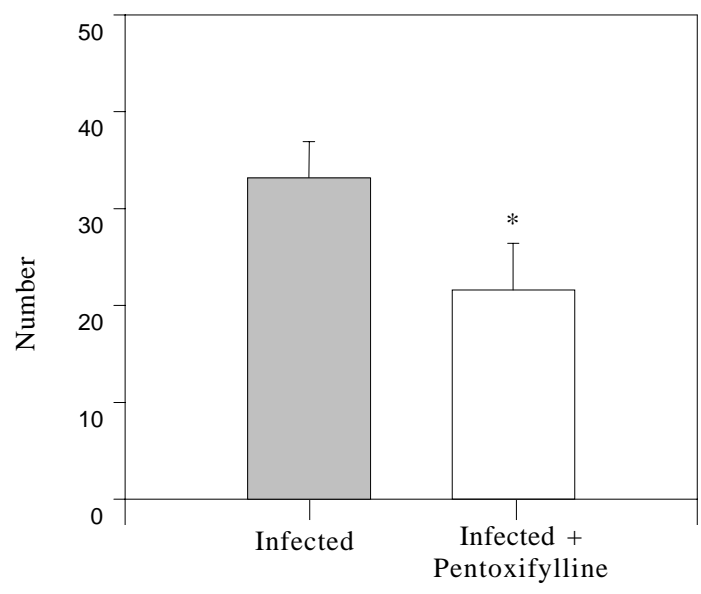

Fig. 2: involutive granuloma number in groups. A significative diminution of hepatic Schistosoma mansoni involutive granuloma number was evident after treatment with pentoxifylline $(\mathrm{p}<0.01)$. 


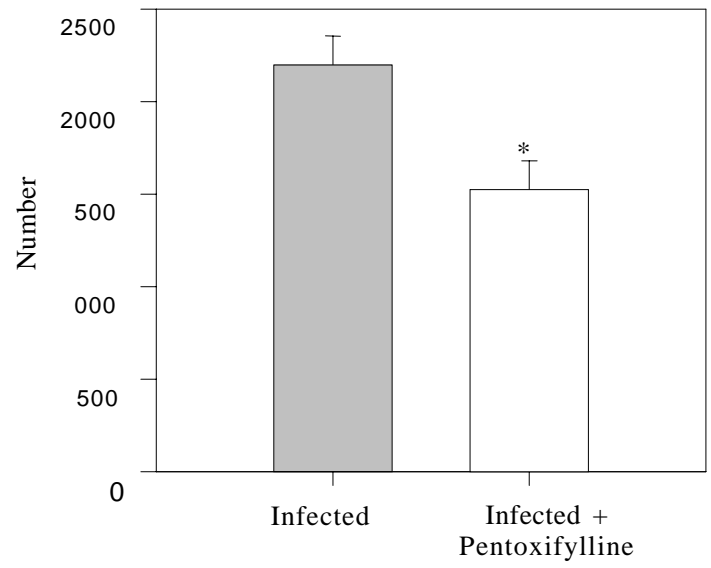

Fig. 3: eosinophils number in infected groups. This graphic shows a significative diminution in the number of intragranulomatous eosinophils after treatment with pentoxifylline $(\mathrm{P}<0.01)$.

Eosinophils were also significatively diminished ( $<<0.01)$ (Fig. 3) in treated animals, while the mast cell population was not affected by the treatment. ( $p>0.05$ ). However, when the number of mast cells was correlated with the number of granulomas, a positive correlation was detected $(\mathrm{r}=0.955)$ (Figs $4,5)$.

In relation to the collagen network, no significative differences were observed between the groups. Collagen arrangement in exudative-productive and in productive granulomas consisted of trellis-like, or storiform, or concentric disposed fibers (Fig. 5A, B, C, D).

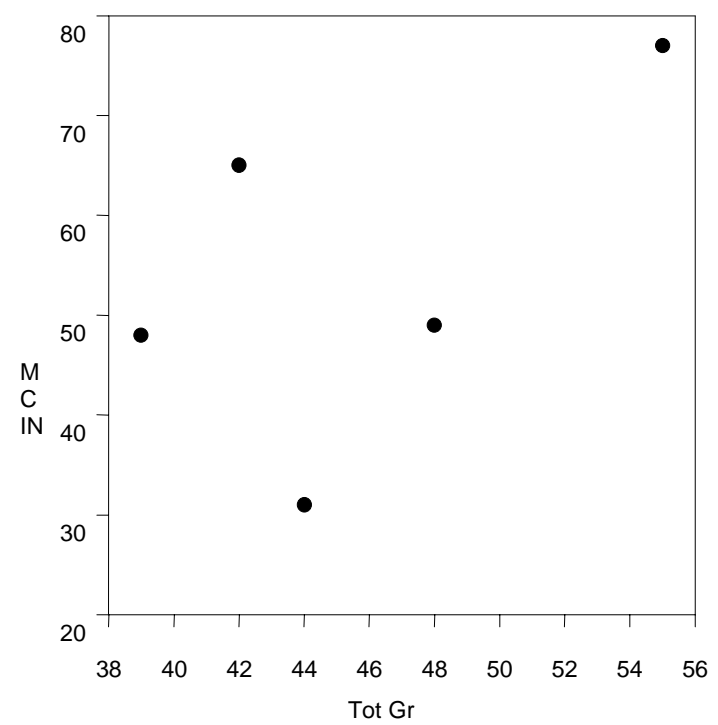

\section{DISCUSSION}

Liver fibrosis is a complex process due to increased synthesis and deposition of extra cellular matrix components (Schuppan et al. 1993). Our results demonstrate that PTX, despite its negative effect on extracellular matrix protein synthesis, reduction of hepatic stellate cells (Pinzani et al. 1996) myofibroblast proliferation (Windmeier \& Gressner 1996), and inhibition of platelet-derived growth factor-driven proliferation of fibroblats (Peterson 1993), did not affect collagen deposition inside murine hepatic S. mansoni granulomas. This lack of effect on collagen synthesis is probably due, in part, to the fact that the drug was administered after granulomas elicitation, when immune competent cells were already stimulated. The decrease in the total number of hepatic granulomas could be due to some toxic effect of the drug on egg release and/or adult worm fecundity (the effect of PTX on adult worm morphology and fecundity is being analyzed). Furthermore, the decrease in the number of involutive granulomas could be paradoxically explained by PTX collagenase stimulation, an aspect already demonstrated by Berman and Duncan (1990), accelerating the time of granuloma disappearance. In fact, PTX can also markedly reduce the expression of the tissue inhibitor of metalloproteinase 1 (TIMP1) mRNA (Romanelli et al. 1997). According to these authors, the antifibrogenic action of PTX on human hepatic stellate cells in response to transforming growth factor-beta 1 (TGF $\beta 1$ ) is mainly mediated by extracellular collagen degradation rather than by a reduction of collagen synthesis.

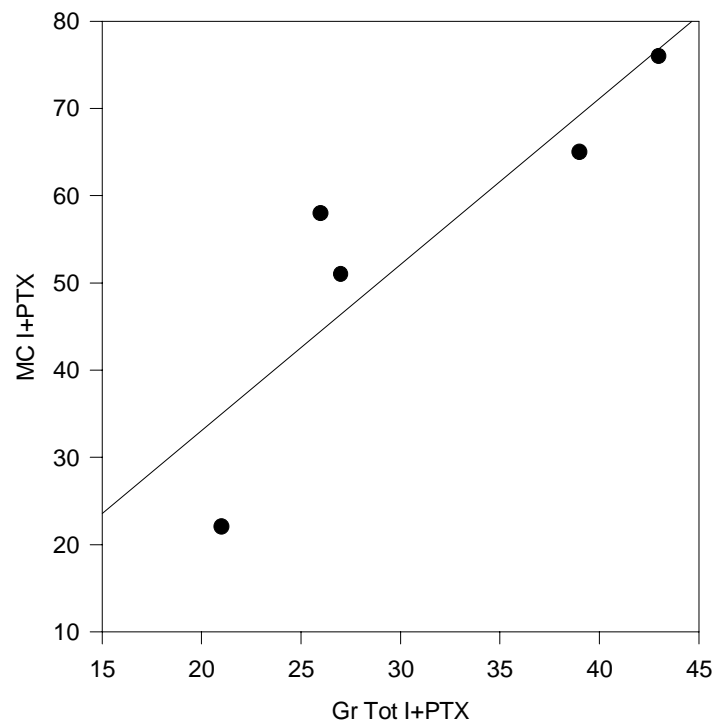

Fig. 4: correlation between mast cells and granulomas. This graphic (right) shows a positive correlation between mast cells and total granuloma numbers (Tot GR INF or Tot GR I+PTX) in animals treated with pentoxifylline $(r=0.955)$ but not in untreated ones $(r=0.507)$. Each point of analysis in $x$ axis represents the total amount of granuloma in one animal. 
PTX also have potent immunossupressive properties, being capable of inhibiting proliferation of mononuclear cells and lymphocytes induced by $\mathrm{T}$ and B-cell mitogens (Rosenthal et al. 1992), reducing indirectly the number of eosinophils which are strongly dependent on T cell cytokines, such as Il3, IL-5 and GM-CSF (Clutterbuck et al.1989).

Although it has been shown that PTX interferes in a variety of experimental models of inflammation that are associated with TNF- $\alpha$ production (Edwards et al. 1992, Hewett et al. 1993) and is capable of blocking mast cell TNF- $\alpha$ synthesis
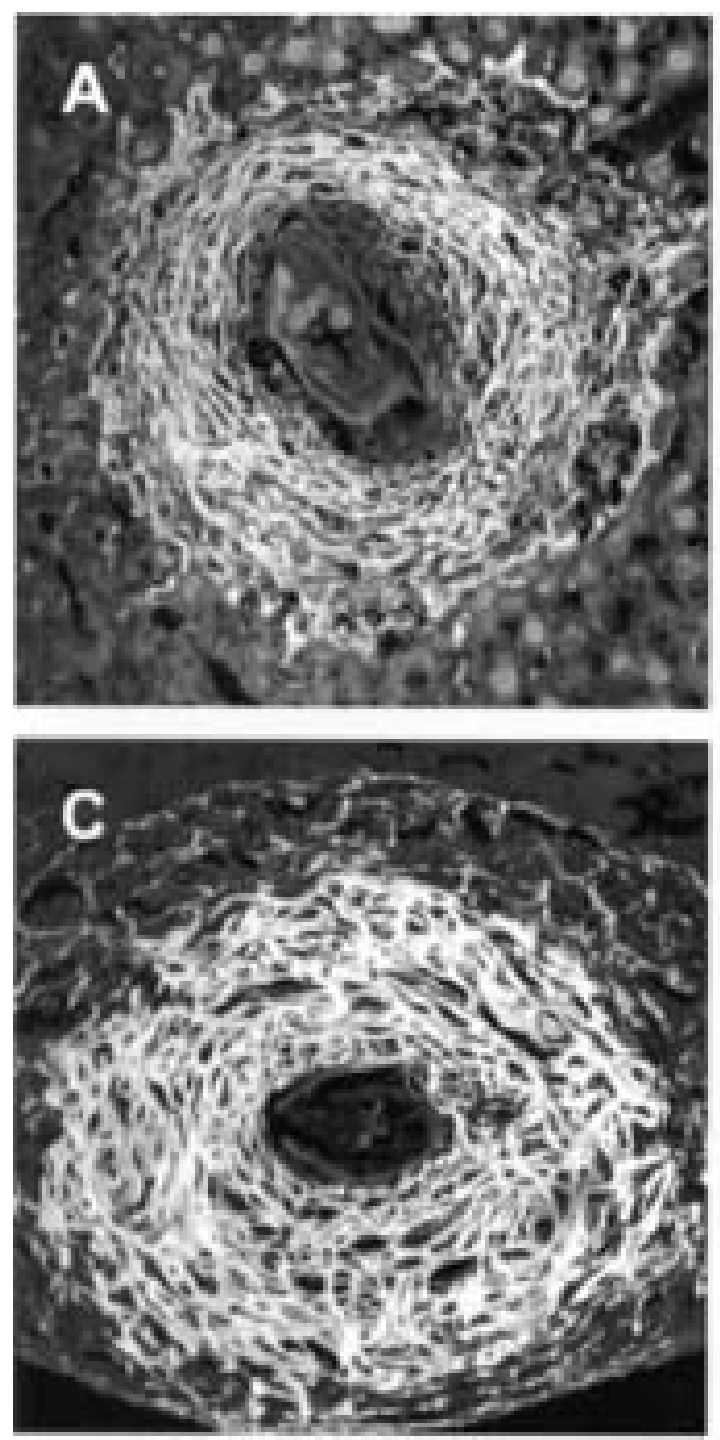
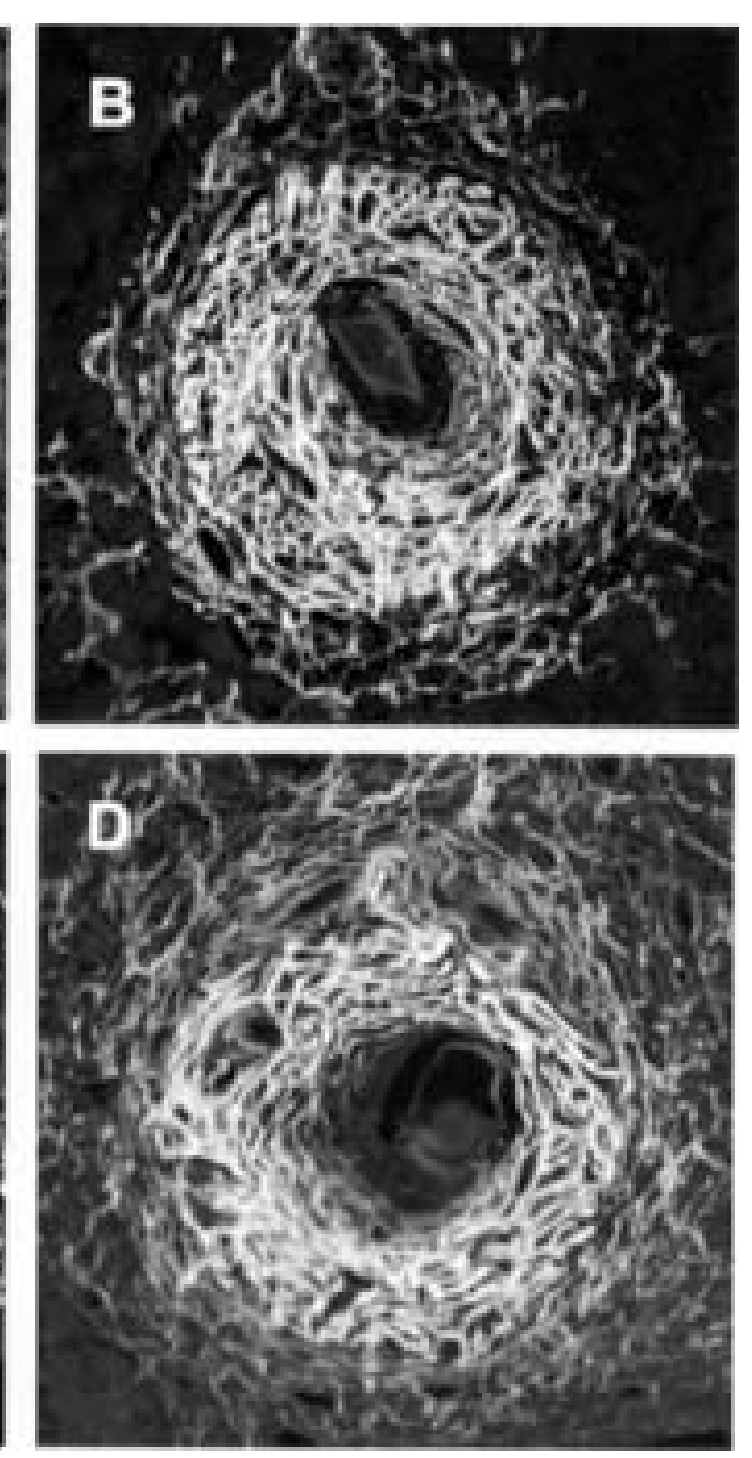

(Schmidt-Choudhury et al. 1996), the effect on mast cell proliferation has not yet been demonstrated. The direct correlation observed between the mast cell and the granuloma numbers indicated that this type of cell was not modulated by PTX. This drug did not have inhibitory effect on spontaneous or induced IL-4 production by short term cultured lymphocytes, indicating a selective sparing of T helper type 2-associated lymphocyte functions (Rott et al. 1993).

This is the first study about the effects of PTX on hepatic S. mansoni granuloma showing that this

Fig. 5: confocal Images The figures shows hepatic granulomas in exudative-produtive stage with similar aspects in both subgroups of infected animals, treated and non-treated with pentoxifylline (PTX). The granulomas are constituted by clear zones: inner or internal or paucifibrillar zone; the middle or paracentral zone, rich in collagen fibers and the outmost or external zone, where the collagen network is more diluted. The images were obtained by CSLM. Figs A and B are related to infected and non-treated subgroup (I), while Figs C and D represent the treated subgroup (I + PTX). 
drug did not alter the intragranulomatous collagen deposition, although it reduced the eosinophil infiltration in the granulomas. Indeed, Sher et al. (1990) have shown that anti-IL-5 antibodies prevented accumulation of eosinophils but have litltle effect on granuloma size or fibrosis.

\section{REFERENCES}

Berman B, Duncan MR 1989. Pentoxifylline inhibits normal dermal fibroblasts in vitro proliferation, collagen, glycosaminoglycan and fibronectin production and increases collagenase activity. Br J Dermatol 123: 339-346.

Bienenstock J, Tomioka M, Stead R, Ernst P, Jordana M, Gauldie J, Dolovich J, Denburg J 1987. Mast cell involvment in various inflammatory process. Am Rev Res Dis 135: 55-58.

Bienvenu J, Doche C, Gutowski MC, Lenoble M, Lepape A, Perdrix JP 1995. Production of proinflammatory cytokines and cytokines involved in the TH1/TH2 balance is modulated by pentoxifylline. J Cardiovasc Pharmacol 25 (Suppl. 2): S80-84.

Bogomoletz W 1980. Avantages de la coloration par le rouge sirius de amyloide et des eosinophiles. Arch Anat Cytol Path 28: 252-253.

Borojevic R, Stocker S, Grimauld JA 1981. Hepatic eosinophil granulocytopoiesis in murine experimental schistosomiasis mansoni. Br J Exp Pathol 62: 480489.

Boros DL, Lukacs NW 1992. The role of egg antigens, cytokine in granuloma formation in murine schistosomiasis mansoni. Mem Inst Oswaldo Cruz 87 (Suppl. IV): 75-79.

Brito JM, Borojevic R 1997. Liver granulomas in schistosomiasis: mast cell-dependent induction of SCF expression in hepatic stellate cells is mediated by TNF- $\alpha$. J Leukoc Biol 62: 389-396.

Cheever AW, Xu Y, Macedonia JG, Cox T, Hieny S, Sher A 1992. The role cytokines in the pathogenesis of hepatic granulomatous disease in Schistosoma mansoni infected mice. Mem Inst Oswaldo Cruz 87 (Suppl. IV): 81-85.

Clutterbuck EJ, Hirst EM, Sanderson CJ 1989. Human interleukin-5(IL-5) regulates the production of eosinophils in human bone marrow cultures: comparison and interaction with IL-1, IL-3, IL-6 and GMCSF. Blood 73: 1504-1512.

Curt MAJ, Samlaska P, Elizabeth CPT, Winfield A 1994. Pentoxifylline: is the pentoxifylline the drug of the decade? J Am Acad Dermatol 30: 603-621.

Davies WB, Fells GA, Sun XH, Gadek JE, Venet A, Crystal RG 1984. Eosinophil-mediated injury to lung parenchymal cell and interstitial matrix. J Clin Invest 74: 269-278.

Dolber PC, Spach MS 1993. Conventional and confocal microscopy of collagen fibers in the heart. J Histol Cytochitol 41: 465-469.

Duncan MR, Hasan A, Berman B 1995. Pentoxifylline, Pentifylline, and Interferons decrease type I and III percolagen $m$ RNA levels in dermal fibroblasts: evidence for mediation by nuclear factor 1 down-regulation. J Invest Dermatol 104: 282-286.
Edwards MJ, Heniford BT, Klar EA, Doak KW, Miller FN 1992. Relationship between tumor necrosis factor-alpha and neutrophils in endotoxin-induced liver injury. J Clin Invest 90: 637-641.

El- Cheikh M, Borojevic R 1993. Extramedular proliferation of eosinophil granulocytes in chronic schistosomiasis mansoni is mediated by a factor secreted by inflamatory macrophages. Infect Immun 58: 816821.

Friedman SL 1993. The celular basis of hepatic fibrosis. N Engl J Med 328: 1828-1835.

Hewett JA, Jean PA, Kunkel SL, Roth RA 1993. Pentoxifylline inhibits interleukin-2-induced toxicity in C57BL/6 mice but preserves antitunior efficacy. Am J Physiol 265: G1011-1015.

Hibbs MS, Mainard CL, Kang AH 1982. Type-specific collagen degradation by eosinophils. Biochem J 207: 621-624.

Isbrucker RA, Peterson TC 1998. Patelet-derived growth factor and pentoxifylline modulation of collagen synthesis in myofibroblasts. Toxicol Appl Pharm 149: 120-126.

Khalil RMD, Luz A, Mailhammer R, Moeller J, Mohamed AA, Omran S, Dörmer P, Hültner L 1996. Schistosoma mansoni infection in mice augments the capacity for interleukin 3 (IL-3) and IL-9 production and concurrently enlarges progenitor pools for mast cells and granulocytes-macrophages. Infect Immun 64: 4960-4966.

Lenzi HL, Kimmel E, Schechman H, Pelajo-Machado M, Vale BS, Panasco MS, Lenzi JA 1998. Collagen arragement in hepatic granuloma in mice infected with Schistosoma mansoni: dependence on fiber radiation centers. Braz J Med Bio Res 32: 639-643.

Lenzi HL, Lenzi JÁ, Rosman FC, Pelajo-Machado M, Mota EM, Panasco MS, Oliveira DN 1997. Extramedullary hematopolesis in murine schistosomiasis mansoni. Mem Inst Oswaldo Cruz 90: 169-177.

Lenzi HL, Sobral ACL, Lenzi JA 1987. In vivo kinects of eosinophils and mast cells in experimental murine schistosomiasis. Mem Inst Oswaldo Cruz 82 (Suppl. IV): 67-76.

Peterson TC 1993. Pentoxifylline prevents fibrosis in an animal model and inhibits platelet-derived growth factor-driven proliferation of fibroblasts. Hepatology 17: 486-498.

Pinzani M, Marra F, Caliguri A, De Franco R, Gentilini A, Failli P, Gentilini P 1996. Inhibition by pentoxifylline of extracellular signal-regulated kinase activation by platelet-derived growth factor in hepatic stellate cells. Br J Pharmacol 119: 1117-1124.

Preaux AM, Mallat A, Rosenbaum J, Zafrani ES, Mavier P 1997. Pentoxifylline inhibits growth and collagen syntesis of cultured human hepatic myofibroblastlike cells. Hepatology 26: 315-322.

Romanelli RG, Caliguri A, Carloni V, De Franco R, Montalto P, Ceni E, Casini A, Gentilini P, Pinzani M 1997. Effect of pentoxifylline on the degradation of procollagen type I produced by human hepatic stellate cells in response to trtansforming growth factor-Beta 1. Br J Pharmacol 122: 1047-1054.

Rosenthal LA, Taub DD, Moors MA, Blank KJ 1992. 
Methylxanthine-induced inhibition of the antigenand superantigen-specific activation of T and B lymphocytes. Immunopharmacology 24: 203-217.

Rott O, Cash E, Fleischer B 1993. Phosphodiesterase inhibitor pentoxifylline, a seletive supressor of $\mathrm{T}$ helper type 1 - but not type 2 - associeted lymphokine production, prevents induction of experimental autoimmune encephalomyelitis in lewis rats. Eur J Immunol 23: 1745-1751.

Schmidt-Choudhury A, Furuta GT, Lavigne JA, Galli SJ, Wershil BK 1996. The regulation of tumor necrosis factor production in murine mast cells: pentoxifylline or dexamethasone inhibits IgE-dependent production of TNF- $\alpha$ by distinct mechanisms. Cell Immunol 171: 140-146.
Schuppan D, Herbst H, Milani S 1993. Matrix, matrix synthesis, and molecular network in hepatic fibrosis. In MA Zern, LM Reid (eds), Extracellular Matrix: Chemistry, Biology, and Pathobiology with Emphasis on the Liver, Marcel Dekker, Inc., New York, p. 201-254.

Sher A, Coffman R, Hieny S, Scott P, Cheever AW 1990. Interleukin 5 is required for the blood and tissue eosiniphilia but not granuloma formation induced by infection with Schistosoma mansoni. Proc Natl Acad Sci USA 87: 61-65.

Windmeier C, Gressner AM 1996. Effect of pentoxifylline on the fibrogenic functions of cultured rat liver fatstoring cells and myofibroblast. Biochem Pharm 51: $577-584$ 